wric "speed." If in any passare arbiglity has thus been occasioned-or, as I would rathe: say, if anything I have thus said can be mistaken-I shall be glad to hear of it and set it right.

I must have failed, however, to make my meaning clear to P. G. T. in pp. 194 and 240. If at least he riglitly understands me, I must leave him to settle with observed facts in one case and with the recognised authorities in the other.

My account of the earlier experiments of Professors Andrews and Tait was taken, as stated, from a paper by Prof. Heaton. I'. G. T. ought to know the facts, and I accept his correction. When my article was written, several years ago, the "now received idea" was not yet received. I did not err in calling that theory "beautiful" and "ingeniously conceived" which is now generally accepted. But if $\mathbf{I}$ had, it is a less serious mistake to describe a sound theory as still open to doubt, than to describe a doubtful theory as demonstrated. This the author of the sea-bird theory of comets might remember with advantage. Richard A. Proctor

\section{Graphic Granite}

I HAVE been spending some time of late in the examination of the rocks of this district, and was pleasantly surprised, a few weeks back, at finding some well-marked specimens of graphic granite among the waste material raised from Hrel Agar Mine. It very closely resembles that found at Portsoy, N.B., but the felspar is grey instead of red. As I am not aware that this interesting rock is known to exist in any other locality in England, the observation may be worthy of record.

W. End, Redruth, December 2

FRANK JOHNSON

\section{The Phonograph and Vowel Sounds}

In the interesting paper on "The Phonograph and Vowel Sounds" (vol. xviii. p. 340, et seq.), the authors remark that although the general results are the same as I have inferred from my own researches, the special numbers expressing the distributiriz of total intensity of vowel sounds among the partial tones are very different. Perhaps you will have the kindness to communicate to your readers the following reasons explaining, as I believe, the differences mentioned above.

I. The tables given by the authors, which contain the distri. bution not of intensity but of amplitudes, must be altered in a maner readily seen in order to be comparable with my tables.

2. The marks impressed by the phonograph contain certain peculiarities which, although without infuence on the tones spoken from the instrument, remain effective in modifying the form of the curves obtained by mechanically transfering them.

3. The objective intensity (kinetic energy) determined by the autirors is nearly, but not quite, proportional to the subjective iatensity (quantity of sensation) which $I$ have measured with the aid of resonators.

4. As I have observed, the differences of English and German pronunciation cause remarkable differences in the distribution of total intensity of vowel sounds among the partial tones.

Taking the above points into consideration it will be seen that the differences mentioned by Messrs. Jenkin and Lwing appear much sinaller.

Besides I am pleased to notice that the authors, like $m y$ self, consider the flexibility of mouth cavity as important in explaining, where it exists, the characteristic pitch and other properties of vowel sounds.

F. AUERBACH

\section{Local Colour-Variation in Lizards}

THIs subject has recently been very fully discussed by my friend, Dr. Max Braun, assistant in the zoological laboratory of the University of Wiirzburg. His paper, which has especial reference to the lizards of Minorca and of some of the smaller islets of the Balearic group which lie round that island, is entitled "Lacerta Lilforti und Lacerta muralis," and will be found in Part I. of the fourth volume of Prof. Semper's "Arbeiten aus dem zoologisch-zootomischen Institut in Würzburg," published in May, 1877.

Braun refers constantly in this paper to a memoir by $\mathrm{J}$. von Beidraga, entitled "Die Faraglione-Eidechse und die Entstehung der Farben bei Eideclisen," which was published at Heidelberg in 1876 .

Eton College, Devember 9

\section{The Range of the Mammoth}

ON November 6 Prof. Boyd Dawkins read a paper before the Geological Society on "The Range of the Malumsth in Space and Time." As the professor and several other recent writers have taken it to be proved that Elephas primigenius occurs iu pre-glaclal bed; it will, perhaps, be as well at once to review the evidence.

GeJlogists often speak of "pre-glacial beds" when they on!y mean beds beneath some one boulder clay, perhaps No. 6 , or even later in the list given below. The succes;ion is roughly as follows :-

6. Hessel Boulder Clay .. Hessel Gravel

5. Purple Boulder Clay ... Bridlington Crar...

4. Chalky Boulder Clay ... Mid-glacial ${ }^{2}$.

3. Contorted Drift ${ }^{1} \ldots$ Sands ${ }^{1}$

2. Second Till ${ }^{\cdots} \ldots$ Intermediate Becls $\mathrm{i}$

1. First Till 1

Arctic Freshwater Beds.

Temperate Freshwater Beds. ${ }^{1}$

$\left.\begin{array}{c}\text { (Land surface.) } \\ \text { Weybourn Beds, estuarine, }\end{array}\right\}$ Pliccena.

including the "Forest Bed."1

As the lozver boulder clay of Northwich, in Cheshire, appears to be No. 5 or No. 6, and consequently newer than the upperboulder clay of East Anglia, the molar of $E$. prinigenius found beneath it need not be pre-glacial. The Hextfordshire boulder clay, beneath which Prof. Prestwich found a tooth is, I believe, No. 4 .

In East Anglia I have seen two molars of $E$. primigenius from the contorted drift, No 3 in the list, but it has not yet beein. found lower. All the specimens said to come from the fores? bed have been dredured or picked up on the beach, and are of no value as evidence. At Bacton, on the Norfulk coast, I dug out a jaw and three teeth of the mammoth from a post. glacial deposit; if the denudation of the cliff; had proceeded these teeth would have been found on the beach mixed wi:h those of $E$. meridionalis. There appears to be one specimen, and one only, found in sitn in the Forest Bed which can witi any probability be referred to $E$. primizenius; this was found some years ago by Mr. Savia, of Cromer, it has not yet been satisfitctorily determined, but from its peculiarity and the difference of opinion about it, it appears certainly not to be the ordinary form.

Egton Bridge, Yarm, Jorks Clement Reid

\section{The Bunsen Flame a Sensitive Flame}

IT is not generally kwown, if it has ever been noticed before, that the Bunsen lamp gives a flame sensitive to sounds. A Iamp should be chosen which has a tendency to "burn below;" this may usually be secured by openiug the air passages to the utmost and lessening the supply of gas. The flame should burn quietly. My most sensitive flume is four inches high; the gas at about one inch pressure of water. A smart tap with a penholder on a glass cylinder a yard from the flame causes the characteristic "ducking," which is so:netimes so energetic as to extinguish the flame or to cause it to burn below. The acute sound of rattling bottles, of a glass rod against a beaker, and many such familiar sounds of the laboratory, are the most effective. This may explain burning below without obvious cause. A tap on a mortar with the pestle twenty feet distant from a well-adjusted flame causes it, and $s s_{\text {, }}$ often unintentionally, we may have the same result.

Preston, December 3

\section{OUR ASTRONOMICAL COLUMN}

JEAN DOMINIQUe CASSINI.-In the course of his examination of the older archives of the Paris Observatory, which had been placed at his disposal with unrestricted permission to make extracts for use in his lunar reCliffs 
searches, in the first instance by Delaunay ancl afterwards by Leverrier, Prof. Newcomb discovered that the widespread belief that Cassini I. was director of the Observatory, which is even stated to have been the fact in French histories of astronomy, is an error. The establishment appears to have been assigned for the common use of the Academy of Sciences, and no such office as that of director was known or recognised. Prof. Newcomb suggests it may have been the celebrity of Cassini which gave rise to the impression that he was director of the Observatory. Of the astronomical records of that time preserved in the archives a large portion were evidently never intended to be understood or used except by the observers themselves. The note-books have no titles, no indications of the observer or indications of the instruments employed, except in the case of clocks: each observer seems to have had his own instruments, without any reference to or comparison with those of others. In the earlier observations no designations even of occulted stars were attached, so that it was necessary for Prof. Newcomb's investigation to calculate the places of the moon as affected by parallax for the times of observation before the objects could be identified, an operation which, though laborious, was always successful except in the cases of a few small stars. Lalande, in his notice of the work of Cassini I., does not call him director of the Observatory at Paris. Louis XIV., he states, applied to the Pope, Clement IX., for permission for Cassini to pass some years in Paris, where the Academy of Sciences was in course of formation, offering him, through Colbert, 9,000 livres per annum for the period of his residence in France. He arrived at Paris on April 4, I669, and his reception by the French king was such that he wished to remain permanently in the country. The Pope offered opposition at first, which the king succeeded in overcoming, and Cassini was naturalised, and, as Lalande says, obtained a considerable fortune. He commenced observations at the Paris Observatory in September, I67I.

THE SECOND COMET OF I 582. - In the list of cometary radiant-points and meteor-showers in the Report for 1877 of the Luminous Meteors' Committee of the British Association, the distance of this comet's orbit at the descending node from the earth's path is stated to be $0 \% 0$, and the conjunction with the cometary shower is fixed to November 9 for 1875 . This is a mistake, whichever orbit of those calculated may be adopted for the comet. Pingré, in his Cometograpkie, gave two sets of elements, the second being calculated apparently with the view to bring in Santucci's reported observation of a comet on March 10, of which he was the only observer. Tycho observed the comet on May 12, 13, and 17 , and it is upon the observations on these three days that the orbits depend. They were reduced with modern elements by Mr. Hind (Astron. Nach. No. 880), and from the resulting positions, D'Arrest calculated elements in 1853 . In 1865 Mr. Marth, after rectifying one oversight in the reduction, also computed an orbit, and his elements will no doubt be preferable to the other systems, though they do not differ materially from D'Arrest's in Astron. Nach., No. 89r. Mr. Marth's elements are as follow :-

Perihelion passage 1582 , May 6.4485 M.T. at Uraniburg.

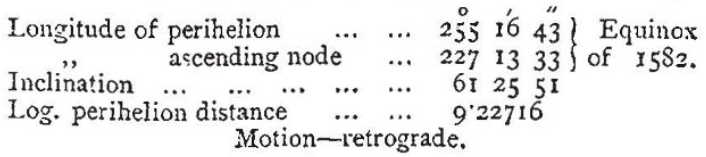

Whence the comet's radius-vector at descending-node is $2: 87$, or the comet is far outside the earth's orbit at that point in its path. The radius-vector at the opposite node is 0.18 , so that there is no near approach to our track.

The comet of 1582 was observed by the Chinese for about twenty day's from the day of discovery, May 20. Their annals have no reference to Santucci's comet, the existence of which is doubtful, but we follow Pingré in designating Tycho's comet-the second of the year.

\section{GEOGRAPHICAL NOTES}

AT the meeting of the Geographical Society on Monday evening, after a few remarks from the Earl of Dufferin, who occupied the presidential chair for the first time, Mr. C. R. Markham, C.B., read three papers on Arctic matters. In the first he treated of the Swedish expedition, of the progress and results of which we have kept our readers informed. The second paper was devoted to the Dutch expedition in the Willem Barents during the past season, the results of which are by no means insignificant. Experience of the ice movements between Spitzbergen and Novaya Zemlya was acquired, and a full hourly series of meteorological observations tal:en, as well as deep-sea soundings with serial temperatures and magnetic observations. Natural history collections were also made, and Mr. W. G. A. Grant, who was in the Pandora in 1876 , succeeded, in spite of almost constant fogs, in completing an excellent series of photographs. Lastly, Mr. Markbam dealt with the best route for future Polar discovery, which he considers to be along the west coast of Franz Josef Land.

WE have to hand a report on the results of the preliminary polar expedition conducted by Capt. Tyson in the Florince. The vessel wintered from C'ctober 10,1877 . in lat. $66^{\circ} 13^{\prime}$, at the bead of Cumberland Gulf, Amisto Hiarbour. The published maps locate this place $2^{\circ}$ further north. Last winter was very severe, almost an unbroken succession of storms of rain and snow. The Filorince was not frozen in until the latter part of November, and after the middle of May the ice was unsafe. The coldest temperature was $-52^{\circ} \mathrm{F}$. on January $2 \mathrm{I}$; the highest, on June 9 , was $55^{\circ} 5$. The longest period of cold was from March 5 to I3, when the thermometer averaged about $-40^{\circ}$. The variations of the thermometer wrere of ten from $6^{\circ}$ to $S^{\circ}$ in a single hour, when the wind was veering. The site had never been visited by any naturalist, but the fauna was found by Mr. Kumlein almost identical with that of Baffin's Bay, with only a few notable and apparently unaccountable exceptions. Some North Pacific species and one European were found by Mr. Kumlein, Birds do not occur in any notable number, except perhaps the eider-duck. Some rare eggs were procured, and a good series of skeletons of young and fotal seals. The flora appears to be extremcly meagre. The same species were collected on the C:eenland coast, in lat. $70^{\circ} \mathrm{N}$., much more luxuriant and abundant. A considerable collection of lichens was made, and a good series of algre was collected. Cnly ten species of fishes were met with, some of them, it is true, of interesting forms. The family collected are of Silurian age. Esquimaux skulls and old implements were procured.

A GOOD deal has been said of late as to the practicability of opening trade-routes to the Chinese province of Yünan from the side of Assam, Burmah, Tonquin, and even Russian Turkestan, and it is, therefore, not uninteresting to note from the Pakhoi Consular Report that the Chinese have a route thither through the south of the empire, of which we believe foreigners have not heard before. Communication between Pakhoi, on the southern sea-board of Kwang-tung, near the Tonquin frontier, and the province of Yünnan is carried on by the west River pass Nanning-fu to Peisi-ting, thence over the mountains, or still by the WVest River, in very small boats, to Kwangnan$\mathrm{ft}$, in Yünnan. In addition to the natural difficulties of the route, the border-land of the two provinces is a wild and lonely region, infested by bands of robvers. The valuable trade which will some day spring up with the rich south-eastern part of Yünnan, not devastated during 